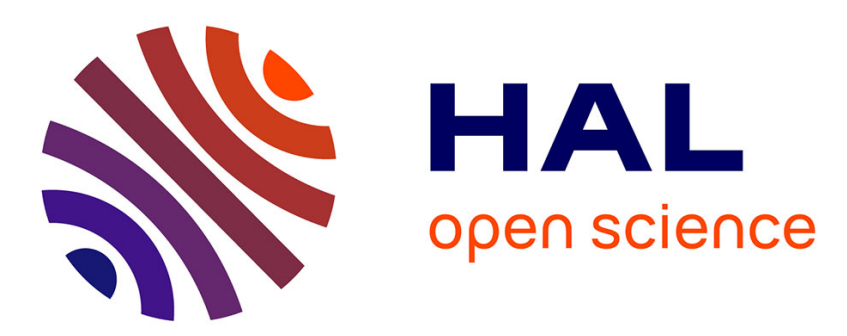

\title{
Inverter Open Circuit Faults Diagnosis in Series-Connected Six-Phases Permanent Magnet Drive
}

Tiago Jose dos Santos Moraes, Mohamed Trabelsi, Ngac Ky Nguyen, Eric

Semail, Fabien Meinguet, Mael Guerin

\section{- To cite this version:}

Tiago Jose dos Santos Moraes, Mohamed Trabelsi, Ngac Ky Nguyen, Eric Semail, Fabien Meinguet, et al.. Inverter Open Circuit Faults Diagnosis in Series-Connected Six-Phases Permanent Magnet Drive. SDEMPED, Aug 2017, Tinos, Greece. pp.1-8. hal-01684104

\section{HAL Id: hal-01684104 https://hal.science/hal-01684104}

Submitted on 15 Jan 2018

HAL is a multi-disciplinary open access archive for the deposit and dissemination of scientific research documents, whether they are published or not. The documents may come from teaching and research institutions in France or abroad, or from public or private research centers.
L'archive ouverte pluridisciplinaire HAL, est destinée au dépôt et à la diffusion de documents scientifiques de niveau recherche, publiés ou non, émanant des établissements d'enseignement et de recherche français ou étrangers, des laboratoires publics ou privés. 


\section{Inverter Open Circuit Faults Diagnosis in Series- Connected Six-Phases Permanent Magnet Drive}

\author{
Tiago José dos Santos Moraes, Mohamed Trabelsi, \\ Ngac Ky Nguyen, Eric Semail, \\ Univ. Lille, Centrale Lille, Arts et Metiers ParisTech, HEI, EA \\ 2697 - L2EP - Laboratoire d'Electrotechnique et \\ d'Electronique de Puissance, F-59000 Lille, France \\ \{tiago.dossantosmoraes, mohamed.trabelsi, eric.semail, \\ ngacky.nguyen\}@ensam.eu
}

\begin{abstract}
This paper deals with the fault effects analysis and diagnosis in 6- $\Phi$ PMSM designed for aerospace applications. The addressed work aims to analyze the features offered by the space vector theory applied to these systems for fault detection and identification purposes. The paper starts with a presentation of the overall electric drive system structure and its control. Then, fault effects analysis under faulty operation mode of the 6-leg voltage source inverter is presented considering the space vector theory. Based on such analysis, an accurate FDI process is designed for these applications. All results are verified analytically and through simulation software using Matlab/Simulink.
\end{abstract}

Keywords- Aerospace safety, six-phase PMSM, multiphase elctric drive, inverter fault effects analysis, fault detection and identification, open-switch fault.

\section{NOMENCLATURE}

$\begin{array}{ll}i_{n} & \text { Phase Currents in abcdef frame } \\ i_{\alpha \beta 1} & \text { Current components in } \alpha \beta 1 \text { frame } \\ i_{\alpha \beta 2} & \text { Currents components in } \alpha \beta 2 \text { frame } \\ i_{h 1}, i_{h 2} & \text { Homopolar current components } \\ \text { PWM } & \text { Pulse-Width Modulation } \\ \text { VSI } & \text { Voltage Source Inverter } \\ \text { FEA } & \text { Fault Effects Analysis } \\ \text { OSF } & \text { Open-Switch Fault } \\ \text { OPF } & \text { Open-phase Fault } \\ \text { FDI Process } & \text { Fault Detection and Identification Process } \\ \text { Back-EMFs } & \text { Back electromotive forces }\end{array}$

\section{INTRODUCTION}

$\mathrm{M}^{2}$ ULTIPHASE machines are interesting in some industrial applications because of their inner fault-tolerance capability to some of the most common drive faults, as openswitch and open-phase faults [1]-[3]. The fault tolerance is due to the higher number of Degrees of Freedom (DoF) for control. The most mentioned drawback of these machines is the supplementary transistors needed to supply all the phases which may increase the system weight, volume and cost.

\author{
Fabien Meinguet \\ Thales Alenia Space - Thales Group, Charleroi, Belgium \\ fabien.meinguet@thalesaleniaspace.com \\ Mael Guerin \\ Thales Avionics Electronics System, Chatou, France \\ mael.guerin@fr.thalesgroup.com
}

A series connected topology is a solution to reduce the number of transistors [4]-[7]. Therefore, by connecting two machines in series the transistors are mutualized, halving its number. In some cases, the series-connected topology may also increase the system performance in degraded mode by reducing the current amplitudes and the torque ripple [5]. In order to assure the independent control of both machines, the machines must at first be multiphase to have enough DoF in order to be able to control each machine. Secondly a special coupling between the two machines, called swapping connection, is needed to decouple them for control purpose. More details are addressed in section II of the present paper.

Even if the multiphase machines are fault tolerant, some effects as unbalanced currents and torque ripples may be constraints for some applications. Consequently, reconfiguration strategies must be achieved to improve the degraded mode and for optimal operation of the electric drive system. The replacement of a faulty transistor is simply implemented, but it demands redundant components and TRIACs in order to isolate the faulty transistor and connect the healthy one to the system, increasing thus the system cost [8]. In the case of two-star 6phase machines, it is possible to disconnect the star supplied by the faulty transistor [9], but it halves the maximum power that the machine may generate. Multiphase machine has DoF that are usually not used in normal functioning mode, but they can be controlled in degraded mode to reduce the torque ripple. Some papers present some reconfiguration control strategies [10].

In order to act in degraded mode, it is necessary to detect the fault mode and the faulty components. The most diagnostic methods addressed in the literature concern the classical drive system based on 3-phase VSIs feeding 3-phase machines. Their evaluation is addressed in [11]-[12]. They are classified as model based methods [13] or signal based methods [12]-[17]. The first ones need an accurate system model to achieve a robust algorithm. Techniques based on analysis of the signals require the measurement of inverter outputs currents or voltages. Methods based on voltage analysis, as addressed in [14]-[19], have a major drawback because an extra hardware or 
extra sensors are usually needed for real time implementation. Methods based on current signals have been reported in [16][20] to multiple open-switch fault. All cited methods cannot be simply applied to the multiphase systems. Firstly, as the power is split to more numerous phases, it can be expected that the detection of open-circuit can be more difficult. Moreover, after a fault occurrence, the modification of the currents in the other phases will not be identical as it is for a wye-coupled 3-phase drive, resulting in false alarms when considering the method developed for the 3-phase systems.

Regarding the multiphase systems, there are only a few works [3], [19] and [20] that address especially the FDI problem for multiphase systems especially under inverter switch faults. Therefore, a 5-phase or an asymmetric 6-phase PMSM was considered. In [3], it is shown that the inverter fault induces a fault current in the second plane $(\alpha \beta 2)$ instead of near zero component under a healthy operation of the VSI. The shape position created by the fault occurrence is used for fault detection and identification. In [19], fault detection algorithm is defined for a BLDC five-machine supplied by the first and third harmonic of currents and with a normalization by the modulus of the measured current vector. The approach is based on an adaptive RLS (Recursive Less Square) identification of each measured current. Errors between the output of adaptive estimation and the one obtained by the model are used for fault diagnostic. In [20], fault detection algorithm is applied to an asymmetric 6-phase PMSM, by analyzing the error between the measured currents and their references.

Concerning the system under study with a particular connection, these methods cannot be applied directly in this case for fault detection and identification. The considered system in this work owns particular characteristics, which will be used to elaborate specific detection methods, as achieved in this work.

Section II presents the series-connected machines topology and the most important equations to understand its mathematical model and control. Section III shows the fault effect analysis on the currents during an OSF and OPF. Section IV describes the FDI process taking into account the current behavior in degraded mode described on Section III.

\section{MODELING AND CONTROL OF THE SERIES-CONNECTED TWO SIX-PHASE PMSM}

The topology analyzed in this paper is depicted in Fig.1. It is composed of two six-phase PMSM connected in series. The sixlegs VSI is fed by a constant voltage source provided through a capacitive dc-link. Each leg regroups two transistors with antiparallel connected freewheeling diodes $\left(\mathrm{T}_{k}, \mathrm{~T}_{k+6}, k=1,2,3,4,5\right.$, 6). The VSI is controlled by the gate switching signals $\left(S_{k}, S_{k+6}\right) \in\{0,1\}$. The gate signal $S_{k}$ or $S_{k+6}$ is equal to "1" when the switch is in "ON" state and equal to " 0 " when the switch is "OFF" state.

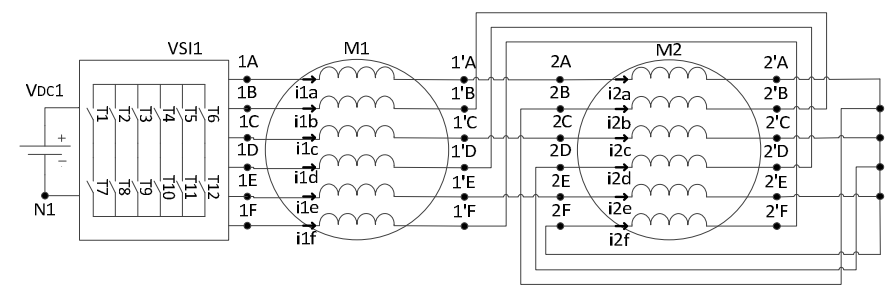

Fig. 1: The dual-machine series connected topology

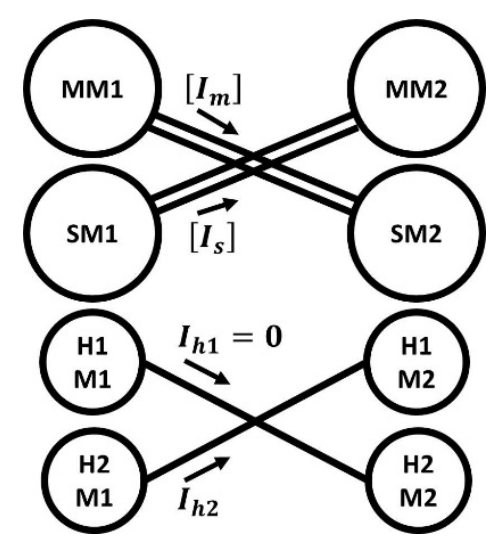

Fig. 2: Equivalent electric couppling of the fictitious machines after the subspace decomposition

TABLE I: Back-EMF harmonic related to each fictitious machine

\begin{tabular}{|c|c|c|c|c|}
\hline $\begin{array}{c}\text { 6-Phase } \\
\text { Machine }\end{array}$ & $\begin{array}{c}\text { First } \\
\text { Homopolar } \\
\text { Machine } \\
\text { (h1) }\end{array}$ & $\begin{array}{c}\text { Secondary } \\
\text { Homopolar } \\
\text { Machine } \\
\text { (h2) }\end{array}$ & $\begin{array}{c}\text { Main } \\
\text { Machine } \\
(\boldsymbol{\alpha} \boldsymbol{\beta})\end{array}$ & $\begin{array}{c}\text { Secondary } \\
\text { Machine } \\
\mathbf{( x ~ y )}\end{array}$ \\
\hline $\begin{array}{c}\text { Back-EMF } \\
\text { Harmonics }\end{array}$ & $\begin{array}{c}\mathrm{H} 0, \mathrm{H} 6, \\
\ldots \mathrm{H} 6 \mathrm{k}\end{array}$ & $\begin{array}{c}\mathrm{H} 3, \mathrm{H} 9, \\
\ldots \mathrm{H} 6 \mathrm{k} \pm 3\end{array}$ & $\begin{array}{c}\mathrm{H} 1, \mathrm{H} 5, \mathrm{H} 7, \\
\ldots \mathrm{H} 6 \mathrm{k} \pm 1\end{array}$ & $\begin{array}{c}\mathrm{H} 2, \mathrm{H} 4, \mathrm{H} 8, \\
\ldots \mathrm{H} 6 \mathrm{k} \pm 2\end{array}$ \\
\hline
\end{tabular}

$[K]$ is defined by

$$
\left[I_{2}\right]=[K]\left[I_{1}\right]
$$

$$
\begin{gathered}
{[\mathrm{K}]=\left[\begin{array}{cccccc}
1 & 0 & 0 & 0 & 0 & 0 \\
0 & -1 & 0 & 0 & 0 & 0 \\
0 & 0 & 1 & 0 & 0 & 0 \\
0 & 0 & 0 & -1 & 0 & 0 \\
0 & 0 & 0 & 0 & 1 & 0 \\
0 & 0 & 0 & 0 & 0 & -1
\end{array}\right]} \\
{\left[\mathrm{C}_{6}\right]=\sqrt{\frac{2}{6}}\left[\begin{array}{cccccc}
1 & \cos \left(\frac{2 \pi}{6}\right) & \cos \left(\frac{4 \pi}{6}\right) & -1 & \cos \left(\frac{8 \pi}{6}\right) & \cos \left(\frac{10 \pi}{6}\right) \\
0 & \sin \left(\frac{2 \pi}{6}\right) & \sin \left(\frac{4 \pi}{6}\right) & 0 & \sin \left(\frac{8 \pi}{6}\right) & \sin \left(\frac{10 \pi}{6}\right) \\
1 & \cos \left(\frac{4 \pi}{6}\right) & \cos \left(\frac{8 \pi}{6}\right) & 1 & \cos \left(\frac{16 \pi}{6}\right) & \cos \left(\frac{20 \pi}{6}\right) \\
0 & \sin \left(\frac{4 \pi}{6}\right) & \sin \left(\frac{8 \pi}{6}\right) & 0 & \sin \left(\frac{16 \pi}{6}\right) & \sin \left(\frac{20 \pi}{6}\right) \\
\frac{\sqrt{2}}{2} & \frac{\sqrt{2}}{2} & \frac{\sqrt{2}}{2} & \frac{\sqrt{2}}{2} & \frac{\sqrt{2}}{2} & \frac{\sqrt{2}}{2} \\
\frac{\sqrt{2}}{2} & -\frac{\sqrt{2}}{2} & \frac{\sqrt{2}}{2} & -\frac{\sqrt{2}}{2} & \frac{\sqrt{2}}{2} & -\frac{\sqrt{2}}{2}
\end{array}\right]}
\end{gathered}
$$


The proposed topology mutualizes the transistors reducing its number by the connection in series. This special electrical coupling allows an independent control of each machine even if they share the same currents. As the phases are star connected on one side, harmonic components (multiple of 6) are null. The proposed series-connected machines imply that the phase currents of each machine are as equation 1.

By decomposing the two series-connected machines in fictitious machines it is easier to understand how the machines' controls are decoupled from each other. Applying 6-phase Concordia transformation defined in (3) to equation (1), a symmetrical six-phase machine is decomposed into four decoupled fictitious machines: two homopolar machines and two diphase machines. Each fictitious machine interacts with some Back-EMFs harmonics to generate torque. In this study, the back-EMFs of the machines analyzed are sinusoidal. Consequently, the main fictitious machines are the only ones able to generate torque. Taking into account the proposed machines connection and Concordia Transformation, the equivalent fictitious machines in the decoupled subspaces are consequently connected as follows:

$$
\left[I_{\alpha \beta x y h 1 \mathrm{~h} 2 \mathrm{~m} 1}\right]=\left[C_{6}\right][K]^{-1}\left[C_{6}\right]^{T}\left[I_{\alpha \beta x y h 1 \mathrm{~h} 2 \mathrm{~m} 2}\right]
$$

Substituting (2) and (3) into (4) gives:

$$
\left[\begin{array}{c}
I_{\alpha \mathrm{m} 1} \\
\mathrm{I}_{\beta \mathrm{m} 1} \\
\mathrm{I}_{\mathrm{xm} 1} \\
\mathrm{I}_{\mathrm{ym} 1} \\
\mathrm{I}_{\mathrm{h} 1 \mathrm{~m} 1} \\
\mathrm{I}_{\mathrm{h} 2 \mathrm{~m} 1}
\end{array}\right]=\left[\begin{array}{cccccc}
0 & 1 & 0 & 0 & 0 & 0 \\
1 & 0 & 0 & 0 & 0 & 0 \\
0 & 0 & 0 & 0 & 1 & 0 \\
0 & 0 & 0 & 0 & 0 & -1 \\
0 & 0 & 1 & 0 & 0 & 0 \\
0 & 0 & 0 & -1 & 0 & 0
\end{array}\right]\left[\begin{array}{c}
I_{\alpha \mathrm{m} 2} \\
\mathrm{I}_{\beta \mathrm{m} 2} \\
\mathrm{I}_{\mathrm{xm} 2} \\
\mathrm{I}_{\mathrm{ym} 2} \\
\mathrm{I}_{\mathrm{h} 1 \mathrm{~m} 2} \\
\mathrm{I}_{\mathrm{h} 2 \mathrm{~m} 2}
\end{array}\right]
$$

Equation (5) implies that the fictitious machines are coupled as follows:

$$
\begin{aligned}
& {\left[I_{\alpha \beta 1}\right]=\left[\begin{array}{l}
I_{\alpha 1} \\
I_{\beta 1}
\end{array}\right]=\left[\begin{array}{l}
I_{\alpha m 1} \\
I_{\beta m 1}
\end{array}\right]=\left[\begin{array}{c}
I_{x m 2} \\
-I_{y m 2}
\end{array}\right]} \\
& {\left[I_{\alpha \beta 2}\right]=\left[\begin{array}{l}
I_{\alpha 2} \\
I_{\beta 2}
\end{array}\right]=\left[\begin{array}{l}
I_{x m 1} \\
I_{y m 1}
\end{array}\right]=\left[\begin{array}{c}
I_{\alpha m 2} \\
-I_{\beta m 2}
\end{array}\right]}
\end{aligned}
$$

In conclusion, it is clear that the main machines are decoupled from each other. The electric coupling is also shown by the scheme of Fig. 2. Consequently, the current components of each main machine are independently controlled, as shown in [5]-[6]. Even if the Back-EMFs were not sinusoidal, this independency of the control of the 2 machines would be assured in regular cases. The secondary machines are only related to Back-EMFs' even-harmonics, which are regularly null because of the symmetry of the rotor.

\section{6-PHASE SERIES-CONNECTED MACHINES POST-FAULT OPERATION ANALYSIS}

In this section, the open-switch fault (OSF) and open-phase fault (OPF) effects analysis (FEA) are addressed. It aims

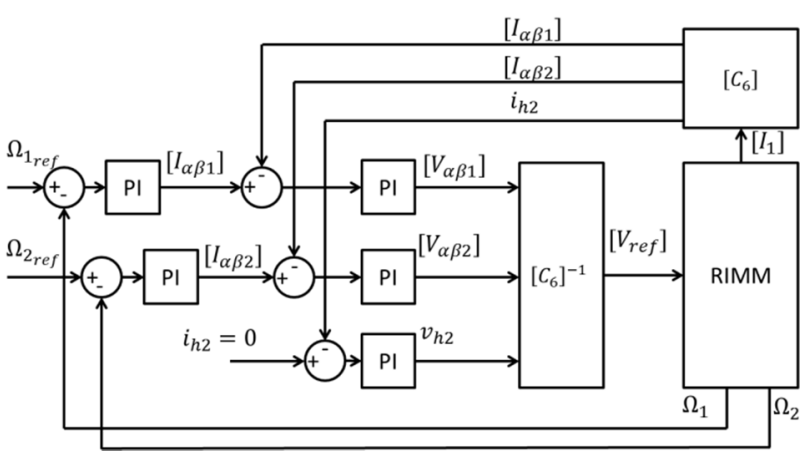

Fig. 3 : Control diagram of a dual-machine connected in series

essentially to provide information about the electric drive system behavior under fault conditions. Here, it should be noticed that is strongly desirable to design a low-cost fault detection and identification (FDI) method. However, it should be suitable the method based on the sensors already available on the electric drive system. This increases consequently the global reliability function of the electromechanical conversion chain and system continuity service, as in the demanding aerospace applications. For this reason, it is chosen in this work that the fault effects analysis will be achieved only regarding the dynamic of the measured phase currents which will be used then as input variables for the real-time FDI process.

The OSF and OPF are among the most common inverter faults [6]. The first one designates a transistor that is blocked at the open state, while the other transistor of the same inverter leg keeps commuting. The second one represents both transistors of the same leg blocked at open state.

In [3], it is shown that OSF can be localized by analyzing the current components repartition in secondary $\alpha \beta 2$-plane when considering only a simple 5-legs inverter feeding only a star connected 5-phase PMSM. With similar reasoning, the analysis will be achieved in the decoupled subspace to have information on the fault occurrence in the VSI. However, considering our application, the secondary subspace cannot be used for fault diagnosis since it is principally used to develop a torque because the series connection of the two 6-phase PMSM, as shown in Fig. 2 .

Results addressed in the next sections are obtained in closed loop control and without reconfiguration of the system after the fault occurrence in the VSI. However, the pre-fault control, as well as the post-fault control, is achieved without change in the speed- and current-loops, as shown in Fig. 3. The reference currents are provided from the outer speed loop and the MTPA strategy.

\section{A. Open-Switch and Open-Phase Faults modes Analysis}

Fig. 4 shows the time-domain waveforms of the phase currents when an OSF occurs in the VSI. The fault is introduced in the transistor T1. In this case, both machines operate at the same speed but different torques. Here, it is observed that the 


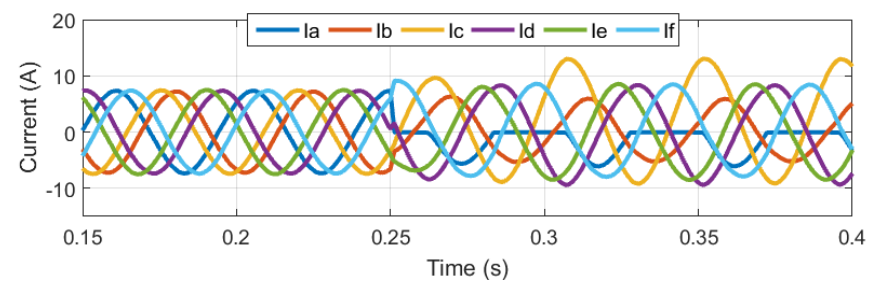

Fig. 4: Currents before and after the opening of T1
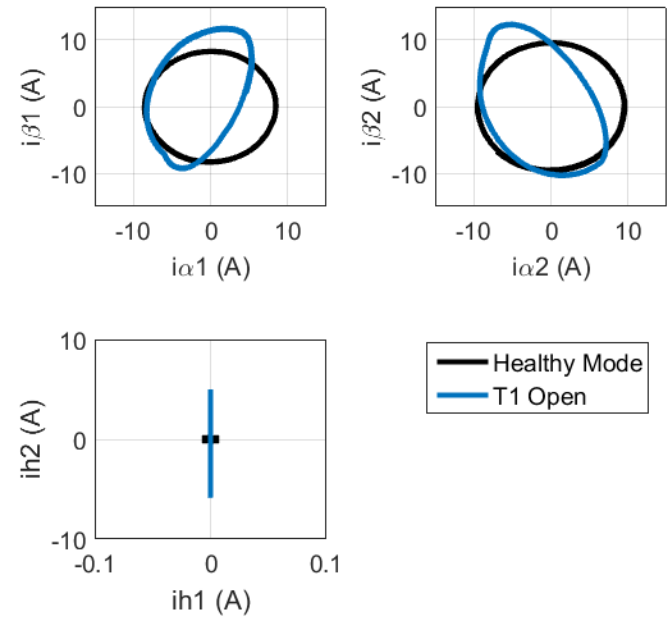

Fig. 5: Current components on the $\alpha \beta 1-, \alpha \beta 2$ - and $\mathrm{H} 1 \mathrm{H} 2$ frames for $\mathrm{T} 1$ open

dynamic performances of the system are affected especially when the current of the faulty inverter leg is nullified (during the interval in which T1 is normally in ON state). During the second half-period, when $i_{a}(\mathrm{t})$ becomes negative, the electric drive system performances are similar to the healthy state.

Now, working in the decoupled subspaces of the 6-phase PMSM, several planes are available for the analysis instead of only one in natural frame. As detailed in section II, these planes are obtained by applying the linear Concordia Transformation. Simulated results of the inverter fault effects analysis in these $\alpha \beta 1$-, $\alpha \beta 2$ - and H1H2-planes are shown in Fig.5. It should be noticed that the third plane, called "H1H2-plane" is voluntary constructed for fault diagnostic purposes. Therefore, two 1Dvariables are merged to form the 2D-plane $\mathrm{H} 1 \mathrm{H} 2$.

The OSF in T1 results in modifications of the current trajectories in decoupled subspaces. A similar behavior is obtained for an OSF in a different transistor as T7 (Fig. 6 and Fig. 7). Therefore, under fault condition, the shapes are no longer circles for $\alpha \beta 1, \alpha \beta 2$ - or zero for $\mathrm{H} 1 \mathrm{H} 2$-plane, as for a healthy operation mode of the VSI. The OSF induces different trajectories in all planes. A particular characteristic is the nonzero current obtained in $\mathrm{H} 1 \mathrm{H} 2$-plane after the fault occurrence, instead of zero in healthy mode. This characteristic together with the information derived from the dynamic of the current vectors in $\alpha \beta 1$ - and $\alpha \beta 2$-planes represent the key point for fault diagnostic process designing.

Regarding the OPF case, it is observed that, from simulation results depicted in Fig. 8, the fault results in zero current in the

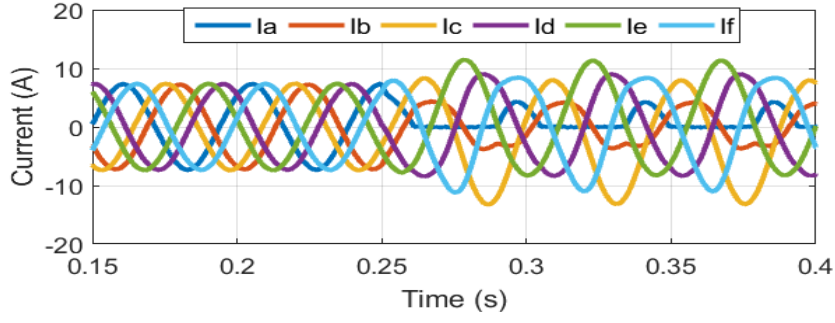

Fig. 6: Currents before and and after the opening of $\mathrm{T} 7$
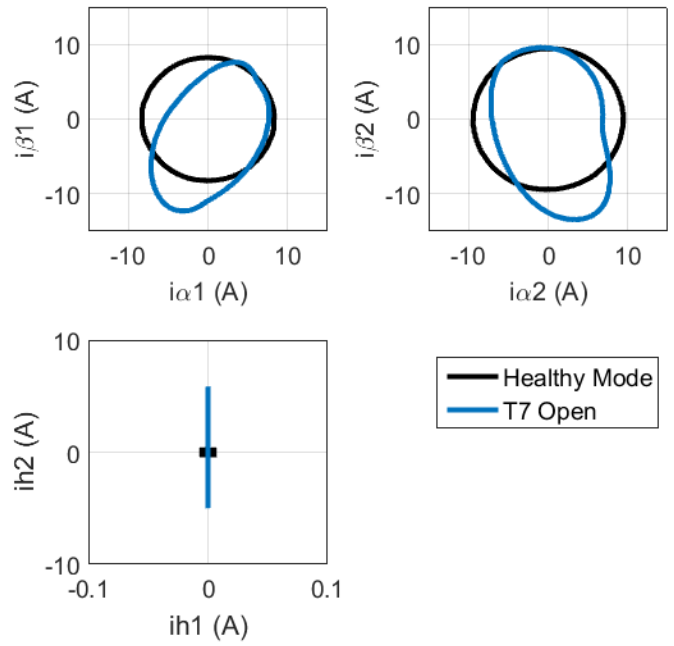

Fig. 7: Current components on the $\alpha \beta 1$-, $\alpha \beta 2$ - and $\mathrm{H} 1 \mathrm{H} 2$ frames for $\mathrm{T} 7$ open

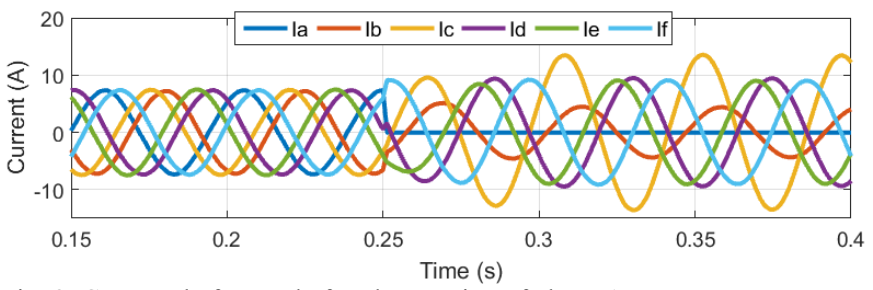

Fig. 8: Currents before and after the opening of phase A
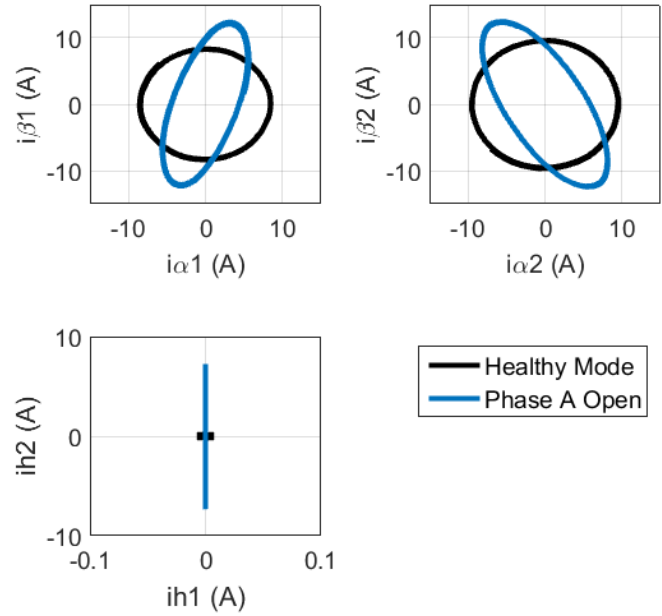

- Healthy Mode

Fig. 9: Current components on the $\alpha \beta 1-, \alpha \beta 2$ - and H1H2 frames for phase A open 
TABLE II: Component current comportment for each frame and each fault mode

\begin{tabular}{|c|c|c|c|c|}
\hline & $\mathbf{k}$ & $\boldsymbol{\alpha} \boldsymbol{\beta} 1$-frame & $\boldsymbol{\alpha} \boldsymbol{\beta}$-frame & $\begin{array}{c}\text { H1H2 } \\
\text { Frame }\end{array}$ \\
\hline \multirow{2}{*}{ Healthy Mode } & & 0 & 0 & 0 \\
\hline \multirow{2}{*}{$\mathbf{T}_{\mathbf{k}}$ open } & odd & \multirow{2}{*}{$(2 \mathrm{k}+5) \pi / 6$} & $(2 \mathrm{k}+5) \pi / 6$ & $\neq 0$ \\
\cline { 5 - 6 } & even & & $(2 \mathrm{k}-1) \pi / 6$ & $\neq 0$ \\
\hline \multirow{2}{*}{$\mathbf{T}_{\mathbf{k}+\mathbf{6}}$ open } & odd & \multirow{2}{*}{$(2 \mathrm{k}-1) \pi / 6$} & $(2 \mathrm{k}-1) \pi / 6$ & $\neq 0$ \\
\cline { 5 - 6 } & even & & $(2 \mathrm{k}+5) \pi / 6$ & $\neq 0$ \\
\hline $\mathbf{T}_{\mathbf{k}}+\mathbf{T}_{\mathbf{k}+\mathbf{6}}$ open & & 0 & 0 & $\neq 0$ \\
\hline
\end{tabular}

faulty phase. In the Concordia frame, the obtained shapes in $\alpha \beta 1$ and $\alpha \beta 2$ planes, Fig. 9, result from the intersection of the shapes corresponding to the single OSF of the involved transistors (T1 and T7).

Finally, it can be concluded that the major differences between the analyzed faults are the average position of the shape in $\alpha \beta 1$ - and $\alpha \beta 2$-frames. These characteristics together with those derived from the $\mathrm{H} 1 \mathrm{H} 2$ plane, are the key point for the detection and localization of the fault since each average position in $\alpha \beta 1$ - and $\alpha \beta 2$-planes corresponds to one OSF or OPF in the VSI. In TABLE II and Fig. 10, it is summarized the different average positions which can be taken by the shapes in $\alpha \beta 1$ - and $\alpha \beta 2$-planes.

As the system is composed by symmetric even-phase machines, there are two phases sharing the same axes in the $\alpha \beta 1$ - and $\alpha \beta 2$-planes, phase $\mathrm{A}$ and $\mathrm{D}$ for example. But thanks to the coupling between the machines, the phases B, D and F (the even phases and switches $(\mathrm{k})$ ) have a different behavior between the $\alpha \beta 1$ - and $\alpha \beta 2$-planes. This difference shows that even if one frame is not enough to localize the faulty switch, each switch has its own signature when combining both frames.

\section{IV.INVERTER OSF AND OPF DIAGNOSTIC}

In this section, the diagnostic procedure is described. The flowchart of design processing algorithm is shown in Fig. 11. The diagnostic procedure consists in three main steps:

- Fault component in decoupled subspace;

- Fault detection;

- Fault location;

The first part consists in obtaining the fault components, which means the current components of each fictitious machine. These quantities are calculated using the measured phase currents and the linear Concordia transformation. The fault detection is obtained by analyzing the homopolar currents in the $\mathrm{H} 1 \mathrm{H} 2$ plane. These currents are the most reliable ones in this case, because they are null in healthy mode. So the detection consists in calculating the detection variable $D_{h}$, expressed by the equation (8) and in comparing it to $D_{t h}$ which denotes the threshold value used to detect the fault occurrence in the VSI.

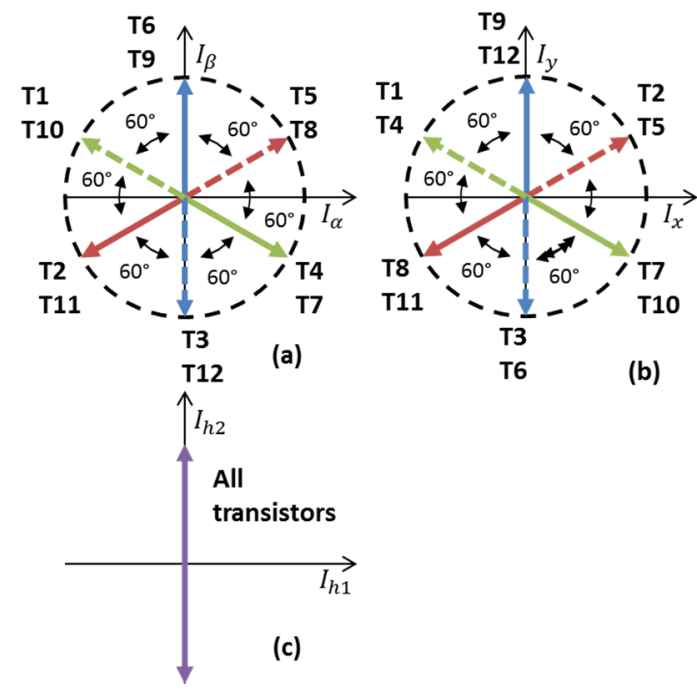

Fig. 10: Faulty shapes average positions in Concordia frame. (a) $\alpha \beta 1$ (b) $\alpha \beta 2$ and (c) $\mathrm{H} 1 \mathrm{H} 2$

TABLE III: FDI Indexes for each Fault Mode

\begin{tabular}{|c|c|c|c|c|c|}
\hline & $\mathbf{k}$ & $\mathbf{D}_{\mathrm{h}}$ & $P_{\alpha \beta 1}$ & $P_{a \beta 2}$ & $\mathbf{O P}_{\mathbf{n}}$ \\
\hline $\begin{array}{l}\text { Healthy } \\
\text { Mode }\end{array}$ & & 0 & 0 & 0 & $>0$ \\
\hline \multirow{2}{*}{$\begin{array}{c}T_{2 k} \\
\text { open }\end{array}$} & odd & \multirow{2}{*}{$>0$} & \multirow{2}{*}{$(2 \mathrm{k}+5) \pi / 6$} & $(2 \mathrm{k}+5) \pi / 6$ & $>0$ \\
\hline & even & & & $(2 \mathrm{k}-1) \pi / 6$ & $>0$ \\
\hline \multirow{2}{*}{$T_{k+6}$ open } & odd & \multirow{2}{*}{$>0$} & \multirow{2}{*}{$(2 \mathrm{k}-1) \pi / 6$} & $(2 \mathrm{k}-1) \pi / 6$ & $>0$ \\
\hline & even & & & $(2 \mathrm{k}+5) \pi / 6$ & $>0$ \\
\hline $\begin{array}{c}\mathbf{T}_{\mathbf{k}}+\mathbf{T}_{\mathbf{k}+6} \\
\text { open }\end{array}$ & & $>0$ & 0 & 0 & 0 \\
\hline
\end{tabular}

As $D_{h}$ is null in healthy mode, $D_{t h}$ value can be quite low, in order to detect the fault as soon as possible.

After the fault detection, three actions are achieved simultaneously; the localization of the shape's average position in $\alpha \beta 1$ - and $\alpha \beta 2$-frames $\left(P_{\alpha \beta}\right.$ and $\left.P_{x y}\right)$ and the calculation of the RMS value of the real currents $\left(O P_{n}\right)$. In equations $(9)-(10)$, it is shown the expressions of the diagnostic variables $P_{\alpha \beta}$ and $P_{x y}$ required by the FDI process. For $P_{\alpha \beta 1}$ and $P_{\alpha \beta 2}$, an error of $\pi / 6$ is tolerate. This step ends by detecting the faulty switch or the faulty phase based on the comparison of the diagnostic variables $P_{\alpha \beta}, P_{x y}$ and $O P_{n}$ to a database specified in TABLE III. Fig. 12 and Fig. 13 address some examples of the fault detection and localization in the VSI based on the defined diagnostic algorithm when an OSF of transistor T1 or an OPF of phase A occur.

$$
\begin{gathered}
D_{h}=\left\langle\sqrt{\left.I_{h 1}^{2}+I_{h 2}^{2}\right\rangle}\right. \\
P_{\alpha \beta 1}=\operatorname{arctg}\left(\frac{\left\langle I_{\beta}\right\rangle}{\left\langle I_{\alpha}\right\rangle}\right) \\
P_{\alpha \beta 2}=\operatorname{arctg}\left(\frac{\left\langle I_{x}\right\rangle}{\left\langle I_{y}\right\rangle}\right)
\end{gathered}
$$




$$
O P_{n}=\sqrt{\left\langle i_{n}^{2}\right\rangle}
$$

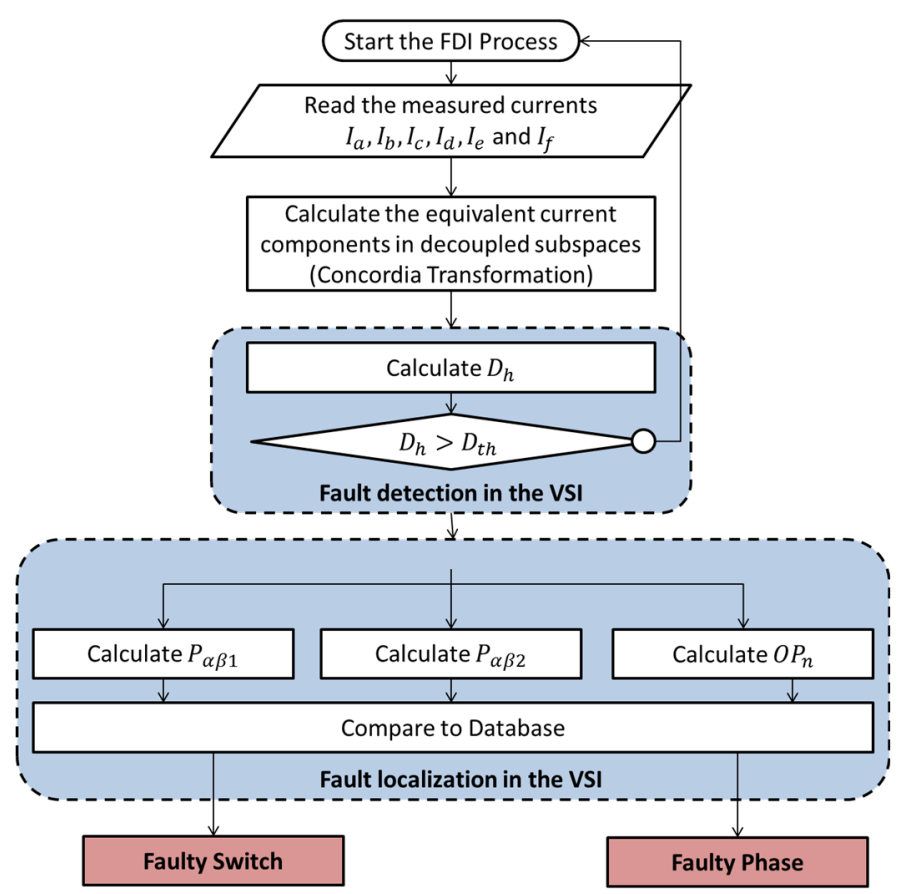

Fig. 11: FDI flowchart

It should be noticed that all the characteristic values used in this method are moving average values computed over one current fundamental period. In addition, for a high performance of the proposed diagnosis method, the measured rotor speed is used to compute the mean values of the defined diagnostic indices.

\section{CONCLUSION}

This method shows a simple and fast diagnosis technique of OSF and OPF occurrence in a 6-leg VSI feeding 2 even-phase PMSM connected in series. Only the measured currents are used for this purpose and no additional hardware or extra sensors are needed by the proposal. The proposed FDI process uses the information derived from the constructed two dimensional homopolar plane $\mathrm{H} 1 \mathrm{H} 3$ combined with the information linked to the current components distribution in $\alpha \beta 1$ - and $\alpha \beta 2$-frames. In fact, as the currents of $\alpha \beta 1$ - and $\alpha \beta 2$-frames control the torque of each machine, $I_{h 2}$ is the only current component that is null on healthy mode and has a distinct value in degraded mode, resulting in a reliable detection variable. Other characteristics are related to the average position of the current trajectories in $\alpha \beta 1$ - and $\alpha \beta 2$-planes are used to identify the faulty transistor.

This paper presented only simulation results. Therefore the experimental verification of the proposed technique constitutes the natural next step.
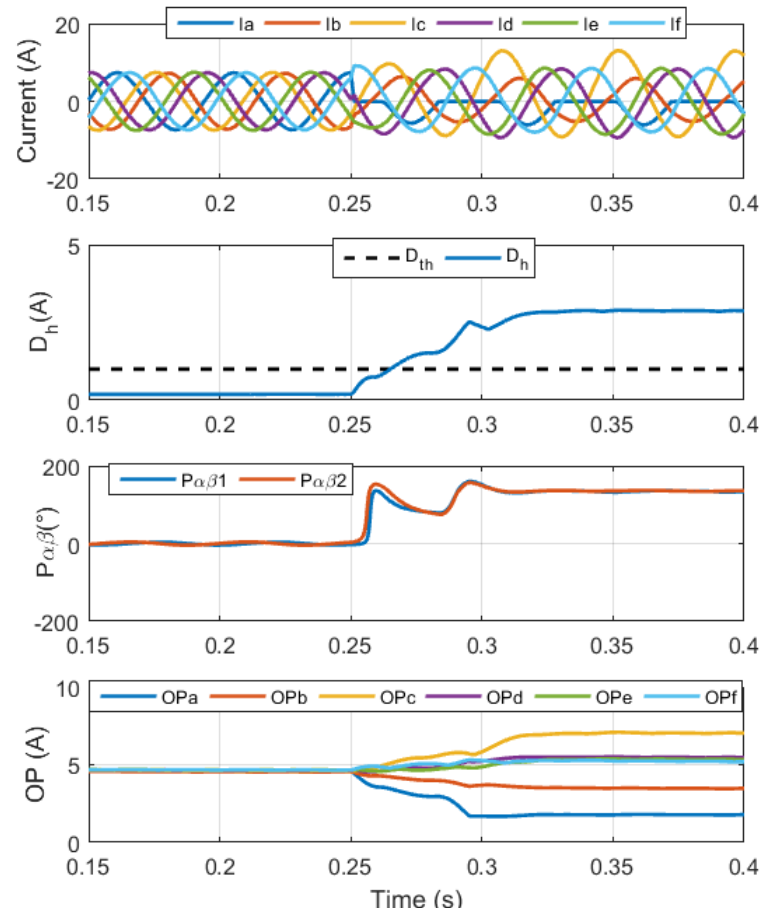

Fig. 12: Time domain waveforms of the phase currents and the diagnostic variables when an OSF of transistor T1 occurs in the VSI while two machines turn at the same speed but with different torques.
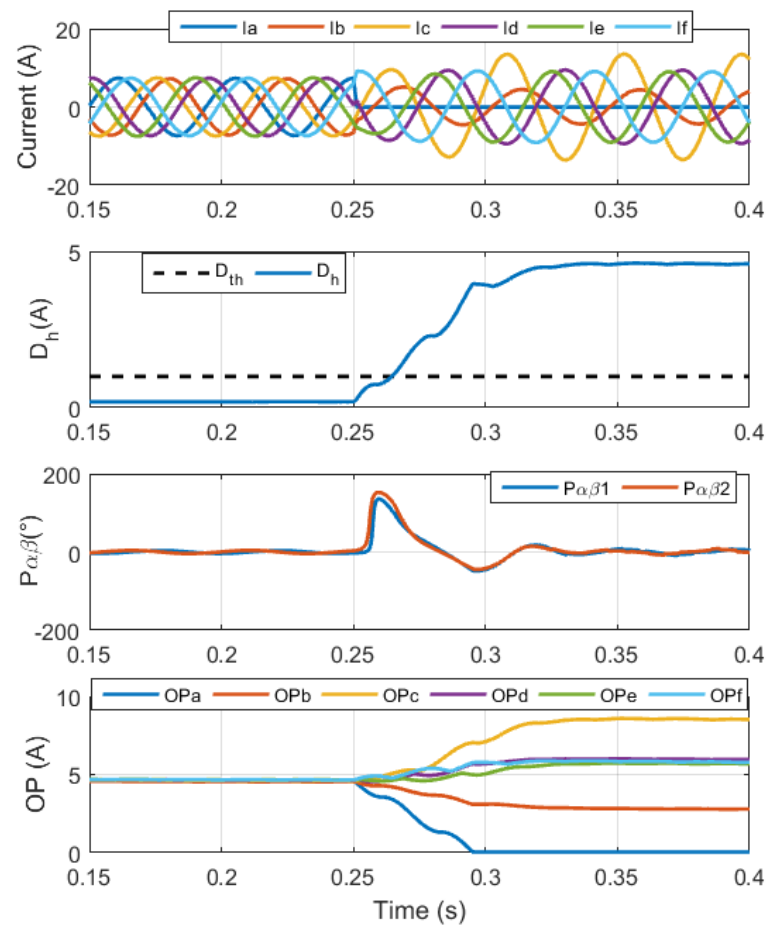

Fig. 13: Time domain waveforms of the phase currents and the diagnostic variables when an OPF of phase A occurs while two machines turn at the same speed but with different torques. 


\section{AKNOWLEDGEMENT:}

This work is a part of a project CE2I supported by FEDER and by the regional council of Hauts de France Region. It has been also supported by Thales Alenia Space.

\section{REFERENCES:}

[1] X. Kestelyn, E. Semail, "A vectorial approach for generation of optimal current references for multiphase permanent-magnet synchronous machines in real time," IEEE Trans. Ind. Electron., vol. 58, no. 11, pp. 5057-5065, Nov. 2011.

[2] M. J. Duran, I. Gonzalez Prieto, M. Bermudez, F. Barrero, H. Guzman, and M. R. Arahal, "Optimal Fault-Tolerant Control of Six-Phase Induction Motor Drives With Parallel Converters," IEEE Transactions on Industrial Electronics, vol. 63, no. 1, pp. 629-640, Jan. 2016.

[3] M. Trabelsi, N. K. Nguyen, E. Semail, "Real-time Switches fault diagnosis based on typical operating characteristics of five-phase permanent magnetic synchronous machines," IEEE Trans. Indus. Electron., vol. 63, no. 8, pp. 4683-4694, Aug. 2016.

[4] E. Levi, R. Bojoi, F. Profumo, H. A. Toliyat, and S. Williamson, "Multiphase induction motor drives - a technology status review," IET Electric Power Applications, vol. 1, no. 4, p. 489, 2007.

[5] T. J. dos Santos Moraes, N. K. Nguyen, F. Meinguet, and E. Semail, "Fault Tolerant Dual-Motor Drives: Sizing of Power Electronic," presented at the EPE'15 ECCE Europe, 2015, pp. 1-10.

[6] T. J. dos Santos Moraes; N. K. Nguyen; E. Semail; F. Meinguet; M. Guerin, "Dual-Multiphase Motor Drives for Fault-Tolerant Applications: Power Electronic Structures and Control Strategies," in IEEE Trans. on Power Electron. , to be published

[7] W. Wang, M. Cheng, B. Zhang, Y. Zhu, and S. Ding, "A Fault-Tolerant Permanent-Magnet Traction Module for Subway Applications," IEEE Trans. Power Electron., vol. 29, no. 4, pp. 1646-1658, Apr. 2014.

[8] R. R. Errabelli and P. Mutschler, "Fault-Tolerant Voltage Source Inverter for Permanent Magnet Drives," IEEE Transactions on Power Electronics, vol. 27, no. 2, pp. 500-508, Feb. 2012.

[9] C. Olmi, F. Scuiller, and J.-F. Charpentier, "Reliability assessment of an autonomous underwater vehicle propulsion by using electrical multi-phase drive," Conference on IEEE Industrial Electronics Society (IECON'15), 2015, pp. 965-970.

[10] N. K. Nguyen, F. Meinguet, E. Semail, X. Kestelyn, "Fault-tolerant operation of an open-end winding five-phase PMSM drive with shortcircuit inverter fault," IEEE Trans. Indus. Electron., vol. 63, no. 1, pp. 595-605, Jan. 2016.

[11] L. Bin, S. K. Sharma, "A literature review of IGBT fault diagnostic and protection methods for power inverters," IEEE Trans. Indus. Appl., vol. 45 , no. 5 , pp. $1770-1777$, Oct. 2009.

[12] Z. Gao, C. Cecati, S. X. Ding, "A survey of fault diagnosis and faulttolerant techniques-Part 1: fault Diagnosis with model-based and signalbased approaches," IEEE Trans. Indus. Electron., vol. 62, no. 6, pp. 37573767, Jun. 2015.

[13] D. U. Campos-Degado, D. R. Espinoza-Trejo, "An observer-based diagnosis scheme for single and simultaneous open-switch faults in induction motor drives," IEEE Trans. Indus. Electron.,vol.58, no.2, pp. 671-679, 2011.

[14] M. Trabelsi, M. Boussak, M. Gossa, "PWM-switching pattern-based diagnosis scheme for single and multiple open-switch damages in VSI-fed induction motor drives," ISA Transactions., vol.51, pp.333-344, 2012.
[15] S. Karimi, A. Gaillard, P.Poure, S.Saadate, "FPGA-based real-time power converter failure diagnosis for wind energy conversion systems," IEEE Trans. Indus. Electron., vol.55, no.12, pp.4299-4308, 2008.

[16] W. Sleszynski, J.Nieznanski, A. Cichowski, "Open-transistor fault diagnostics in voltage-source inverters by analyzing the load currents," IEEE Trans. Indus. Electron., vol.56, no.11, pp.4681-4688, 2009.

[17] J. O. Estima, A. J. Marques Cardoso, "A new algorithm for real-time multiple open-circuit fault diagnosis in voltage-fed PWM motor drives by the reference currents errors," IEEE Trans. Indus. Electron., vol. 28, no. 5, pp. 3496-3505, Aug. 2013.

[18] M. Trabelsi, M. Boussak, M. Benbouzid, "Multiple criteria for high performance real-time diagnostic of single and multiple open-switch faults in ac-motor drives: Application to IGBT-based voltage source inverter, " Electric Power System research, vol.144, pp.136-149, march 2017.

[19] M. Salehifar, R. S. Arashloo, J. M. Moreno-Equilaz, V. Sala, L. Romeral, "Fault detection and fault tolerant operation of a five phase PM motor drive using adaptive model identification approach," IEEE J. Emerging Sel. Top. Power Electron, vol. 2, no. 2, pp. 212-223, Jun. 2014.

[20] G. R. Catuogno, G. O. Garcia, and R. Leidhold, "Fault tolerant control in six-phase PMSM under four open-circuits fault conditions," Conference on IEEE Industrial Electronics Society (IECON'16), 2016, pp. 5754-5759. 